\section{Práticas de planejamento e implementação de políticas no âmbito municipal}

\author{
Municipal health policy planning and \\ implementation
}

\footnotetext{
${ }^{1}$ Departamento de Saúde, Universidade Estadual de Feira de Santana, Feira de Santana, Brasil. 2 Instituto de Saúde Coletiva, Universidade Federal da Bahia, Salvador, Brasil.

Correspondência A. L. Q. Vilasbôas Departamento de Saúde, Universidade Estadual de Feira de Santana. Rua Manoel Gomes de Mendonça 307, apto. 2401 Salvador, $B A$ 41810-820, Brasil. anav@ufba.br
}

\begin{abstract}
Municipal health policy planning can include exemplary practices for expanding the population's access to health services. The current study seeks to analyze the limits and possibilities of planning practices for policy implementation by a municipal health department. The empirical data were analyzed based on a concept of planning practices and the theoretical link between the three spheres of government and the postulate of coherence. The use of unstructured strategic planning practices by the management team allowed a significant expansion in the supply of services to the population, but lacked the scope to overcome the limits imposed on the organization's governability by the health services funding model, characterized by strong induction from the federal level. The project was the most robust vertex in the government triangle and led to the development of initial expertise by the municipal management team, thereby ensuring a certain level of governability over the health project. The goals of increasing the supply of health services were constrained by the method's weakness and the organization's institutional insipience.
\end{abstract}

Health Planning; Health Management; Health Policy; Local Health Systems
Ana Luiza Queiroz Vilasbôas 1

Jairnilson Silva Paim 2

\section{Introdução}

No âmbito governamental, o ciclo de políticas é um modo de representação do complexo processo que envolve a construção de uma determinada decisão e sua execução. A implementação de políticas é um dos momentos desse processo, implicando a operacionalização das decisões tomadas em torno do que fazer para enfrentar problemas ou atender necessidades, identificadas a partir da relação entre Estado e sociedade 1 .

Tratar a implementação de políticas de saúde como objeto de investigação pressupõe desvendar os modos pelos quais ocorrem as conexões entre a formulação de diretrizes políticas e sua operacionalização nos serviços de saúde 2 . As conexões referidas podem estar mediadas pelo planejamento, no sentido que lhe é atribuído como parte da gestão dos sistemas e serviços de saúde 3 , na medida em que se constitui como um meio para desenhar, organizar e acompanhar a execução de proposições destinadas a operacionalizar decisões institucionais.

Evidências da literatura internacional indicam a precária incorporação do planejamento à gestão de instituições públicas de saúde em países ocidentais 4 , especialmente a partir da década de 90, em que se fortaleceu o pensamento da Nova Direita que propugnava a retirada do Estado na provisão de serviços de saúde 5 .

No Brasil, o processo de implantação do Sistema Único de Saúde (SUS) tem colocado a ges- 
tão como o elemento central da implementação das políticas de saúde, o modo concreto de operá-las, mediante processo de negociação entre os dirigentes das três esferas administrativas. A partir do final dos anos 90, as características do processo de descentralização das ações e serviços de saúde colocaram os municípios habilitados na forma de gestão plena do sistema de saúde como protagonistas na execução das políticas definidas nos foros intergestores de negociação. Essa forma de gestão tem-se constituído, portanto, como espaço privilegiado da implementação das políticas de saúde.

Estudos realizados sobre a descentralização do sistema de saúde no Brasil 6,7 têm destacado as complexas relações intergovernamentais na formulação e implementação das políticas de saúde, apontando para o forte papel indutor exercido pelo Governo Federal, mediante mecanismos de transferências de recursos financeiros para os municípios em função de sua adesão a determinadas políticas, negociadas nas instâncias intergestores.

Apesar do aumento da capacidade gerencial dos municípios, especialmente daqueles em gestão plena do sistema 8, a complexidade institucional da conformação do SUS, composto por três esferas de governo que são autônomas e, ao mesmo tempo, interdependentes 9 , traz restrições que podem explicar a limitada incorporação do planejamento à formulação de políticas de saúde nesse âmbito, revelada pelas evidências encontradas na literatura 10,11.

Entretanto, não foram encontrados estudos que revelem possíveis contribuições do planejamento ao modo de conduzir as ações de saúde no âmbito municipal, para alcançar os objetivos previstos nas políticas pactuadas em outras instâncias governamentais do SUS. Dada a necessidade institucional de organizar um conjunto variado de ações de saúde com vistas ao cumprimento dos princípios constitucionais, podese admitir, inicialmente, que, em experiências municipais bem-sucedidas quanto à ampliação do acesso da população aos serviços de saúde, haveria o exercício de práticas de planejamento para implementar políticas de saúde.

Este estudo buscou analisar os limites e as possibilidades de práticas de planejamento na implementação de políticas de saúde, em um contexto municipal exitoso de gestão plena do sistema de saúde, no período de 2001 a 2004.

\section{Elementos teóricos}

O planejamento, em geral, e o planejamento em saúde, em particular, apresentam várias denomi- nações nas literaturas nacional e latino-americana. O planejamento tem sido designado como um processo social, um método, uma técnica, uma ferramenta ou tecnologia de gestão, um cálculo que precede e preside a ação, um trabalho de gestão, uma mediação entre as diretrizes políticas de uma organização e a subjetividade dos trabalhadores 12,13,14,15. Contudo, o que há de comum nessas definições é a idéia do planejamento como uma forma de orientação da ação humana, dirigida para o alcance de uma dada finalidade. Nesse sentido, o planejamento é uma ação social 16, pois tem uma estrutura teleológica que lhe é inerente 17.

Em uma dimensão técnica, que não exclui seu caráter social, o planejamento consiste na transformação de um objeto em um produto, vinculado a uma dada finalidade, o que implica trabalho humano. Nessa transformação opera a tecnologia 18. Essa formulação aproxima o planejamento do conceito de processo de trabalho e permite abordá-lo como um determinado tipo de trabalho, aquele que organiza outros trabalhos para a realização dos propósitos institucionais 2 .

No caso específico em que o objeto desse trabalho são as práticas de saúde realizadas em uma instituição, pode-se admitir que as práticas de planejamento agiriam sobre a organização das práticas de saúde de modo a torná-las coerentes com os princípios orientadores da ação institucional, contribuindo para a implementação das políticas de saúde nesse âmbito. A transformação desse objeto seria operada pela tecnologia, que, nesse caso, expressar-se-ia mediante a utilização de saberes operantes 2 , inspirados em técnicas e conhecimentos disciplinares, e saberes práticos, construídos "em ato", para organizar a realização de práticas de saúde, com propósitos de manutenção ou transformação da situação de saúde.

O componente tecnológico das práticas de planejamento, constituído por saberes operantes e saberes práticos, pode assumir a conformação de um cálculo sistemático, articulando o conhecimento com a ação e o presente com o futuro. A depender do grau de formalidade do cálculo 13 , poderá haver várias formas de expressão tecnológica das práticas de planejamento: um formato estruturado, mediante procedimentos formalizados para a elaboração de propostas de ação cotejadas com a análise da situação, fundamentadas em análises de coerência, suficiência e viabilidade das proposições; um formato não estruturado, constituindo-se como um cálculo estratégico sistemático, sem atender a requisitos de formalidade.

As finalidades postas para o planejamento estariam vinculadas a propósitos de legitimação dos atores sociais e de manutenção ou transfor- 
mação da situação 19, e, assim, moldariam o conteúdo de seus produtos. Orientariam, também, as ações de construção de viabilidade política das propostas formuladas pelos atores em questão.

Ao se considerar que o trabalho também é interação social, as relações sociais entre os sujeitos "planejadores" no ato de planejar podem revelar a racionalidade que os mesmos imprimem às suas ações: estritamente teleológica ou instrumental, quando considera o outro como um objeto, que reage ao que propõe, sem uma condução própria, a fim de obter êxito; estratégica, uma outra forma de racionalidade teleológica, que considera a existência de outros atores que também planejam, mas, mediante cooperação ou conflito, tenta impor-lhes o seu propósito, que é a busca do êxito; e, comunicativa, quando estabelece um diálogo com o outro para compartilhar uma interpretação sobre a situação em foco, e, desse modo, construir consensualmente um propósito comum, mediante atos de fala sustentados por pretensões de validade 17 .

O planejamento enquanto trabalho de gestão para a implementação de políticas pode ser investigado, considerando o triângulo de governo 13 , como aproximação ao plano empírico. $\mathrm{O}$ triângulo de governo é um sistema formado pela articulação de três variáveis, mutuamente condicionadas e interdependentes: projeto, capacidade de governo e governabilidade. As práticas de planejamento seriam um dos componentes da capacidade de governo e, desse modo, condicionariam e seriam condicionadas pelo projeto de governo e pela governabilidade do sistema.

Para a construção do quadro teórico dessa investigação, partiu-se do pressuposto de que o triângulo de governo possa dialogar com o postulado de coerência, considerando-se os propósitos de uma instituição e o método que utiliza 19. Segundo tal postulado, os propósitos de uma instituição, os métodos que utiliza para alcançá-los e a organização que assume devem ser coerentes. Há relações de determinação e condicionamento entre os três elementos do postulado, que, por sua vez, seriam sobredeterminados pela história, pelo papel do Estado e pela teoria. Em contextos de desenvolvimento econômico dependente, os propósitos de uma instituição seriam determinados pelo papel do Estado e determinariam seu método e a organização. Essa última condicionaria o método e os propósitos institucionais e seria determinada pela história. A teoria determinaria o método, sendo determinada também pela história e pelo papel do Estado. O método, por sua vez, pode determinar a organização nas situações em que essa apresenta um alto grau de labilidade institucional.
A noção de método indicada no postulado de coerência pode ser considerada um dos componentes da capacidade de governo. No presente estudo, pretende-se explorar teoricamente uma articulação entre o postulado de coerência e o triângulo de governo, no sentido de possibilitar a análise das práticas de planejamento em uma instituição responsável pela implementação de políticas num contexto municipal de relativa autonomia na execução das ações de saúde.

Os formatos estruturados e não estruturados das práticas de planejamento realizadas por sujeitos, trabalhadores e dirigentes de uma instituição de saúde, seriam uma das possíveis traduções do método, um dos componentes da capacidade de governo. As práticas de planejamento estariam dirigidas a organizar práticas de saúde, uma das formas de implementar políticas de saúde. As práticas de planejamento seriam condicionadas pela organização, caracterizada pelas estruturas e formas de organização do trabalho realizado pelos dirigentes e trabalhadores; e determinadas pelos propósitos de ambos quanto aos resultados de suas práticas: legitimação, manutenção, crescimento, mudança ou transformação. E não estariam livres de determinações mais amplas, como o papel do Estado e da história (Figura 1).

Pode-se afirmar, provisoriamente, que o estudo de práticas de planejamento numa Secretaria Municipal de Saúde (SMS), na medida em que é um dos componentes da capacidade de governo, deve levar, também, em consideração as relações de tais práticas com o conteúdo propositivo dos projetos de ação, o projeto de governo, e com o grau de controle de variáveis decisivas para a ação da equipe dirigente da SMS, a governabilidade. Ao mesmo tempo, os processos de definição do conteúdo propositivo dos projetos de ação são influenciados pelas práticas de planejamento, que, também, modulam a análise e construção cotidiana da viabilidade política do projeto de governo, expressão da governabilidade do sistema (Figura 1).

\section{Metodologia}

A insuficiência de estudos empíricos que pudessem revelar limites e possibilidades da incorporação de práticas de planejamento para a implementação de políticas de saúde no âmbito municipal levou à escolha de um estudo de caso único, de caráter exploratório, que permitisse a caracterização do objeto do estudo e uma interpretação de suas propriedades. A escolha do município estudado ocorreu em função de seu desempenho, considerado um exemplo de situ- 


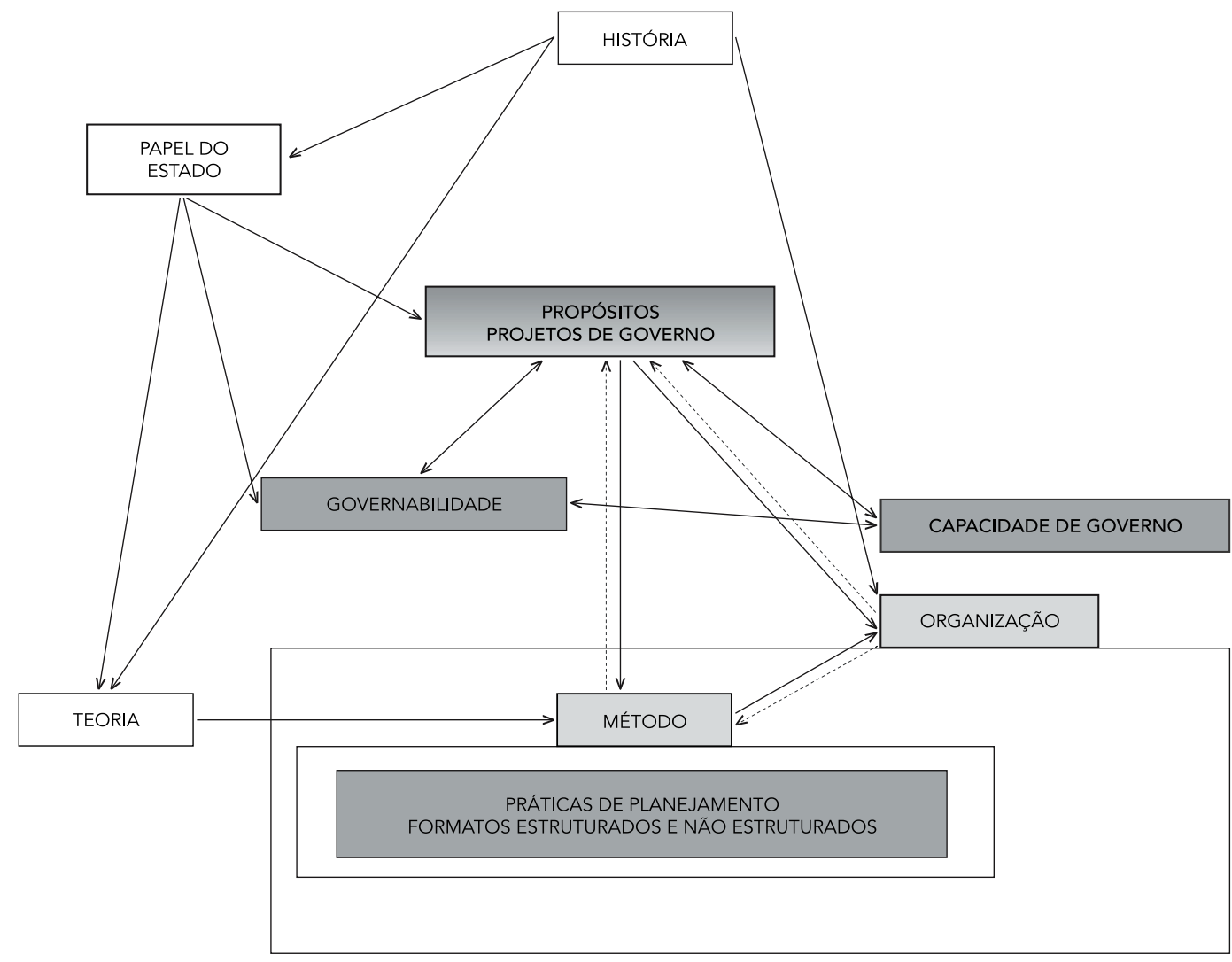

Nota: setas cheias - relações de determinação; setas tracejadas - relações de condicionamento; setas duplas - relações interdependentes.

ação avançada no processo de descentralização da gestão do sistema municipal de saúde 20 .

O município estudado situava-se em um estado do Nordeste brasileiro, com população estimada de 277.659 habitantes em 2004 e área geográfica de $3.743 \mathrm{~km}^{2}$. Segundo o Plano Diretor de Regionalização do Estado, o município era sede de uma macrorregião de saúde. Porém, sua responsabilidade em prestar atendimento de média e alta complexidade e ofertar internações hospitalares ultrapassava os limites geográficos dessa macrorregião, atingindo 75 municípios, o que correspondia a uma população estimada em cerca de 1,5 milhão de habitantes. A oferta desses serviços, associada à força do comércio local, tornou o setor terciário responsável por cerca de $50 \%$ da renda da população.

O município habilitou-se na gestão plena da atenção básica em março de 1998 e na gestão ple- na do sistema municipal de saúde em outubro de 1999, segundo a legislação atinente à matéria. O processo de municipalização possibilitou a expansão significativa da oferta de ações e serviços de saúde aos munícipes e à população da macrorregião da qual o caso era sede.

O estabelecimento de um conceito de práticas de planejamento e a articulação teórica entre o triângulo de governo e o postulado de coerência possibilitaram a identificação e definição das unidades de análise, categorias operacionais e variáveis que compuseram o plano de análise do estudo (Tabelas 1 e 2), base para a construção dos roteiros da análise documental, entrevistas semi-estruturadas com informantes-chave e observação. A investigação foi aprovada pelo Comitê de Ética do Instituto de Saúde Coletiva da Universidade Federal da Bahia, com base na Resolução $n^{o}$. 196/96 do Conselho Nacional de 
Plano de análise: práticas de planejamento.

\begin{tabular}{|c|c|c|}
\hline Unidade de análise & Categoria operacional & Variáveis \\
\hline \multirow{5}{*}{$\begin{array}{l}\text { Práticas de } \\
\text { planejamento }\end{array}$} & Práticas de planejamento & Procedimentos institucionalizados para a elaboração de propostas \\
\hline & estruturadas & de ação incorporando momentos formais de acompanhamento e \\
\hline & & avaliação das propostas para sua revisão sistemática \\
\hline & Práticas de planejamento & Cálculo estratégico sistemático, sem mecanismos formais de operacionalização, \\
\hline & não estruturadas & baseado em elementos teóricos, metodológicos e ideológicos \\
\hline \multirow{8}{*}{$\begin{array}{l}\text { Componentes } \\
\text { das práticas de } \\
\text { planejamento }\end{array}$} & Objetos & Práticas de saúde executadas pela SMS \\
\hline & Produtos & Organização das práticas de saúde, conforme os princípios assistenciais do SUS \\
\hline & Meios/Tecnologias: saberes operantes & Conhecimentos, técnicas utilizadas pelos dirigentes e equipes técnicas \\
\hline & & para organizar práticas de saúde \\
\hline & Meios/Tecnologias: saberes práticos & $\begin{array}{l}\text { Conhecimentos e técnicas produzidas no ato de planejar a organização } \\
\text { das práticas de saúde }\end{array}$ \\
\hline & Relações sociais entre dirigentes e equipes & Relações de cooperação, cooptação ou conflito entre dirigentes e equipes \\
\hline & técnicas estabelecidas durante o exercício & técnicas estabelecidas durante o exercício das práticas de planejamento \\
\hline & das práticas de planejamento & \\
\hline
\end{tabular}

SMS: Secretaria Municipal de Saúde; SUS: Sistema Único de Saúde.

Saúde. O trabalho de campo foi desenvolvido em novembro de 2004, o que possibilitou o acesso a documentos, a observação de algumas práticas de planejamento e gestão da SMS e a realização de 27 entrevistas com dirigentes e técnicos da Prefeitura Municipal.

As entrevistas foram gravadas pela autora, com o consentimento dos entrevistados. Cada entrevista foi analisada, procurando, num primeiro momento, classificar os extratos do texto que expressassem os modos de pensar dos informantes, segundo as categorias analíticas. De posse da classificação do conjunto de extratos das entrevistas, foram construídos outros textos sobre cada palavra-chave. O ordenamento do material coletado das entrevistas permitiu a identificação de convergências e divergências, no interior dos discursos dos informantes, que foram comparadas com as evidências retiradas dos documentos analisados e do diário de campo com o registro das observações realizadas pela autora durante o período de coleta de dados no campo. Foi possível, então, caracterizar certas representações dos entrevistados a respeito do objeto do estudo.

A triangulação das evidências foi efetivada mediante um cuidadoso trabalho de comparação entre os discursos registrados nos documentos oficiais com os achados das entrevistas e da observação, na busca de evidências negativas às hipóteses iniciais do estudo. As evidências foram comparadas com o plano de análise, adotandose o uso da estratégia de análise denominada de "pareamento de um modelo", na qual o pesquisador elabora o quadro teórico da intervenção para ser a base de comparação com os achados do estudo 21 .

\section{O triângulo de governo da Secretaria Municipal de Saúde}

O projeto de governo da administração municipal, conduzido pelo mesmo partido político desde 1997, centrou-se na ampliação da oferta das ações de saúde, educação e assistência social à população. A decisão política em favor desses setores ocorreu não só pela opção de responder às necessidades da população pelo consumo desses serviços, como pela possibilidade real de ampliação de recursos financeiros, assegurados pela legislação e por políticas específicas do Governo Federal.

Os mesmos propósitos de governo para o setor saúde eram compartilhados pelo núcleo dirigente da administração municipal (equipe dirigente e técnicos da SMS). Considerando o período do estudo (2001-2004), a maioria dos entrevistados destacou o propósito de crescimento quanto ao projeto de governo, no sentido de ampliação, diversificação e melhoria da qualidade da oferta de serviços de saúde.

A equipe dirigente da SMS tinha certa governabilidade sobre o sistema municipal de saúde, na medida em que contava com apoio político do Governo Federal, do núcleo dirigente da ad- 
Plano de análise: triângulo de governo e postulado de coerência.

\begin{tabular}{|c|c|c|}
\hline Unidade de análise & Unidade de análise & Variáveis \\
\hline \multirow[t]{2}{*}{ Governabilidade } & $\begin{array}{l}\text { Autonomia administrativa } \\
\text { e financeira da SMS }\end{array}$ & $\begin{array}{l}\text { Execução direta, pela SMS, dos procedimentos de aquisição de bens e serviços } \\
\text { relacionados com ações de saúde: presidência da Comissão de Licitação da } \\
\text { Saúde, realização de empenho, liquidação e pagamento dos processos licitatórios }\end{array}$ \\
\hline & $\begin{array}{l}\text { Apoio político ao projeto de } \\
\text { governo da SMS quanto à organização } \\
\text { das ações de saúde }\end{array}$ & $\begin{array}{l}\text { Apoio legislativo ao projeto de governo da SMS; apoio do Conselho Municipal } \\
\text { de Saúde ao projeto de governo da SMS; apoio da mídia ao projeto de governo } \\
\text { da SMS quanto à organização das ações de saúde; apoio dos profissionais da SMS } \\
\text { ao projeto de governo da SMS }\end{array}$ \\
\hline Projeto de governo & $\begin{array}{l}\text { Suficiência e coerência das propostas } \\
\text { de organização das ações de saúde }\end{array}$ & $\begin{array}{l}\text { Suficiência e coerência das diretrizes políticas e objetivos explicitados com } \\
\text { os princípios do SUS e com as propostas do governo municipal }\end{array}$ \\
\hline \multirow[t]{2}{*}{ Capacidade de governo } & $\begin{array}{l}\text { Experiência da equipe } \\
\text { dirigente da SMS/perfil } \\
\text { da direção }\end{array}$ & $\begin{array}{l}\text { Média de anos trabalhados da equipe em processos de organização das ações } \\
\text { de saúde; existência de liderança ou quadro político na direção do setor saúde; } \\
\text { formação do dirigente na área de saúde coletiva; concepção do dirigente sobre } \\
\text { o sistema de saúde coerente com os princípios do SUS }\end{array}$ \\
\hline & $\begin{array}{l}\text { Habilidades da equipe } \\
\text { dirigente da SMS } \\
\text { Acervo de métodos e } \\
\text { técnicas de condução }\end{array}$ & $\begin{array}{l}\text { Formação profissional em saúde coletiva e participação anterior ou atual da } \\
\text { equipe dirigente em movimentos políticos, associativos, profissionais } \\
\text { Práticas de planejamento executadas pela equipe dirigente e pelas equipes } \\
\text { técnicas investigadas }\end{array}$ \\
\hline Propósitos & $\begin{array}{l}\text { Intenções da instituição quanto } \\
\text { à permanência, crescimento ou } \\
\text { mudança da situação atual }\end{array}$ & $\begin{array}{l}\text { Movimentos realizados pela equipe dirigente para legitimar-se, } \\
\text { permanentemente, junto ao poder executivo, poder legislativo, } \\
\text { mídia e trabalhadores de saúde } \\
\text { Suficiência e coerência do conteúdo propositivo do projeto de governo quanto } \\
\text { ao crescimento ou mudança da situação atual }\end{array}$ \\
\hline Organização & $\begin{array}{l}\text { Estruturas e formas de organização } \\
\text { do processo de trabalho da equipe } \\
\text { dirigente e das coordenações/ } \\
\text { equipes técnicas investigadas }\end{array}$ & $\begin{array}{l}\text { Estruturas organizativas da SMS; tipos e periodicidade dos encontros de } \\
\text { trabalho; mecanismos de tomada e execução das decisões }\end{array}$ \\
\hline Método & $\begin{array}{l}\text { Práticas de planejamento executadas } \\
\text { pela equipe dirigente e coordenações/ } \\
\text { equipes técnicas investigadas }\end{array}$ & $\begin{array}{l}\text { Racionalidades: normativa, estratégica e comunicativa; práticas estruturadas } \\
\text { de planejamento; práticas não estruturadas de planejamento }\end{array}$ \\
\hline
\end{tabular}

SMS: Secretaria Municipal de Saúde; SUS: Sistema Único de Saúde.

ministração municipal, do Conselho Municipal de Saúde e do setor privado vinculado ao SUS. Sofria oposição política do governo estadual, Câmara de Vereadores e dos principais órgãos da mídia local. Quanto aos servidores da SMS, havia um apoio instável, dependente da garantia de condições adequadas de trabalho e de melhorias salariais. As demais secretarias da administração municipal resistiam às iniciativas de articulação intersetorial demandadas pela SMS para o atendimento de reivindicações dos representantes dos usuários nos Conselhos Locais de Saúde, presentes em grande parte das unidades de Saúde da Família e das unidades básicas tradicionais.

A SMS gozava de relativa autonomia administrativo-financeira. Entretanto, apesar de ser a gestora do Fundo Municipal de Saúde e de presidir a Comissão Especial de Licitação da Saúde, a SMS compartilhava a gestão dos procedimentos administrativos, orçamentários e financeiros com as secretarias de Planejamento, Finanças e Administração. Os procedimentos de todas as secretarias eram centralizados na Prefeitura Municipal por decisão política de ambos os prefeitos (2001-2002 e 2003-2004), justificada em nome da racionalização de recursos e da unidade de comando da administração municipal. Entretanto, havia problemas de superposição de funções.

Parecia ocorrer ineficiência na condução compartilhada dos processos de licitação de bens e serviços, considerando as queixas de desabastecimento de itens essenciais ao funciona- 
mento das unidades da rede municipal de saúde. A demora na aquisição de bens e serviços para a SMS era atribuída, também, a problemas com a centralização da contabilidade, com a insuficiência do fluxo de caixa, gerado pelos atrasos de repasse de recursos federais, e com a ausência de priorização dos gastos devido à existência de vários ordenadores de despesa na SMS.

A distribuição das funções entre a equipe dirigente e os técnicos do nível central da SMS não estava vinculada a estruturas formais e cargos correspondentes. Havia um organograma informal que orientava a composição de coordenações técnicas, responsáveis pelo controle, apoio ou execução das ações de saúde realizadas pelo sistema municipal de saúde. Havia, também, coordenações responsáveis pelo suporte administrativo e financeiro e pela operação dos sistemas de informação.

A equipe dirigente da SMS foi se constituindo no processo de assunção das responsabilidades institucionais pela gestão plena do sistema de saúde. Se, por um lado, esse formato contribuía para uma certa horizontalidade nas relações de trabalho entre os gerentes da SMS, por outro lado, gerava muitos conflitos causados pela indefinição de papéis, particularmente entre as áreas técnicas e a área administrativo-financeira.

A ausência de encontros periódicos de trabalho para a definição de critérios para a alocação de recursos também contribuía para aumentar os conflitos entre as coordenações técnicas e a coordenação administrativo-financeira da SMS. As relações entre profissionais das áreas técnicas e da área administrativa fundamentavam-se em uma racionalidade estritamente teleológica. Não havia o reconhecimento mútuo da necessidade de construir acordos sobre a forma como os procedimentos administrativos deveriam ser realizados.

A perícia da equipe dirigente da SMS, um dos componentes de sua capacidade de governo, foi sendo construída a partir da decisão política da administração municipal de implantar a gestão plena do sistema de saúde. O perfil dos entrevistados que compunham a equipe dirigente da SMS revelou um grupo de profissionais com história de envolvimento político em associações profissionais, movimento estudantil e partidos políticos. Eram sujeitos constituídos na militância. Esse conjunto de profissionais reunidos em torno do projeto da municipalização da saúde foi se capacitando no processo, acumulando conhecimentos e experiências que ampliaram sua perícia no governo, configurando uma maior legitimidade ao projeto que defendiam.

Entretanto, apesar da qualificação técnica específica, observava-se, na maioria dos profis- sionais vinculados às coordenações responsáveis pela organização da atenção à saúde, uma insuficiência de conhecimentos sobre a gestão dos processos administrativos. Constatou-se, também, na administração municipal, uma certa precariedade de práticas estruturadas de planejamento e gestão de compras de insumos e de contratos de serviços, indispensáveis ao bom funcionamento da rede pública de unidades de saúde.

A falta de controle sobre o financiamento da saúde, visto que as regras eram definidas no âmbito federal, a quem cabia o repasse dos recursos financeiros aos municípios, também influenciava a capacidade de governo da SMS, provocando restrições ao seu desempenho administrativo. Ademais, a universalização do atendimento, desvinculada de mecanismos de controle mais efetivos sobre a oferta de procedimentos, exigia a ampliação dos gastos sem a possibilidade de aumentar o financiamento.

\section{Práticas de planejamento da Secretaria Municipal de Saúde}

Foi possível identificar a existência de práticas de planejamento com distintos formatos e racionalidades na SMS. O processo de elaboração dos instrumentos de planejamento governamental e parte do planejamento de determinadas ações de atenção básica, nos níveis central e local do sistema municipal de saúde, aproximavam-se da noção de práticas estruturadas de planejamento, na medida em que dispunham de uma determinada padronização normativa, externa ou interna à organização, com graus variáveis de formalização.

Foram identificadas práticas mais flexíveis e informais, no sentido de não disporem de uma estrutura metodológica bem definida, mais próximas da noção de cálculo estratégico e de ação comunicativa, que poderiam ser tratadas, para efeito desse estudo, como práticas não estruturadas de planejamento.

O acompanhamento do processo de trabalho das equipes locais, realizado por determinados técnicos da Coordenação da Atenção Básica, configurava-se como prática de planejamento que apresentava elementos de uma prática comunicativa. Era uma ação fundamentada na construção de um projeto comum a esses profissionais, em que cada atividade planejada era originada de um acordo obtido mediante consenso entre esses sujeitos que compartilhavam um mesmo código de conduta no trabalho, caracterizado pela escuta das demandas das equipes e pela disponibilidade de apoiarem seus profissionais na construção 
de propostas de enfrentamento dos problemas identificados.

A observação do processo de trabalho do Secretário de Saúde, no momento da coleta dos dados, reiterada pelos achados das entrevistas com os dois Secretários e o Subsecretário do período 2000-2002, revelou o exercício de um cálculo cotidiano para a construção da viabilidade do projeto de governo da saúde. Não se tratava de um cálculo sistemático pleno, na medida em que não dispunha de uma fundamentação teórica e de ferramentas metodológicas explícitas, apesar de dispor de elementos ideológicos bem definidos, visto que o compromisso ético e político com a consolidação do SUS no município eram muito claros.

Esse cálculo era fundamentado na capacidade da equipe dirigente da SMS em convencer, obter a cooperação e cooptar outros atores relevantes para o projeto da saúde. Tal capacidade vinculava-se à legitimidade técnica e política desse ator social. Tratava-se de um cálculo essencialmente estratégico, pois visava à obtenção do êxito na consolidação do SUS no município e no fortalecimento político do partido que administrava o município, com a ampliação de sua influência para a macrorregião, da qual era sede para a prestação de atendimento médico de média e alta complexidade.

Esse cálculo pode ser definido como uma prática de planejamento, um tipo de trabalho da gestão, porque nele podem-se identificar os seguintes elementos constitutivos: um objeto, a oferta de serviços de saúde à população; um produto, a viabilidade política da ampliação da oferta de serviços de saúde; uma finalidade, a consolidação do SUS municipal; um meio de trabalho, o saber prático produzido em ato por seus agentes na interação com atores sociais que tinham também interesse sobre aquele objeto; e um conjunto de atividades, as diversas formas de negociação realizadas pelos agentes com esses atores.

Os resultados do estudo apontam para o predomínio da racionalidade estratégica nas práticas de planejamento realizadas para fora da SMS. Essa constatação guarda coerência com o contexto político-institucional no qual a SMS estava inserida, caracterizado pela existência de atores sociais com interesses contraditórios.

Internamente à SMS, predominava a racionalidade estratégica, além da comunicativa, ainda que em menor grau e mais localizada. A racionalidade estratégica era a marca em determinadas relações entre profissionais de saúde, nos movimentos empreendidos por técnicos para obterem apoio à implementação das políticas de atenção à saúde, em ambas as direções: nível central - nível local e vice-versa. A racionalidade comunicativa se revelava entre um pequeno grupo de profissionais que compartilhavam o mesmo modus operandi na tentativa de realizar a supervisão das equipes de saúde da família, das quais saíram para apoiar a organização da atenção básica no nível central da SMS.

Entre os meios utilizados para o exercício das práticas de planejamento identificadas, verificou-se que o saber, nas modalidades operante e prático, era a tecnologia estruturante desse trabalho. O saber operante, traduzido em conhecimentos sobre saúde coletiva e administração pública. O saber prático, exercido pelos sujeitos que planejavam, em duas situações. A primeira, nos momentos em que os acordos em torno do "que fazer" ocorriam com uma racionalidade estratégica ou teleológica, na maioria das situações, ou de modo comunicativo, num caso específico, entre determinados técnicos da Coordenação da Atenção Básica. A segunda situação, revelada pela criação de um conjunto de passos metodológicos para a execução das práticas de planejamento, a exemplo de roteiros para a condução de reuniões; da adaptação de técnicas para levantamento de problemas e elaboração de propostas de intervenção sobre os mesmos; e da articulação programática entre distintos instrumentos de planejamento governamental (Plano Plurianual de Governo, Agenda e Quadro de Metas e Plano Municipal de Saúde).

\section{Discussão}

As práticas de planejamento da SMS, identificadas neste estudo, apresentavam um baixo grau de institucionalização, realizando-se em momentos pontuais, em espaços circunscritos da organização. Uma exceção a essa tendência foi o cálculo técnico-político realizado pelos Secretários e Subsecretário de Saúde, prática não estruturada de planejamento. O referido cálculo era dirigido para o êxito e inspirava-se nos princípios ético-políticos que norteavam a implantação do SUS, conferindo-lhe, enquanto ação social, uma determinação racional, com dupla face: técnica, na medida em que se baseava numa racionalidade, predominantemente, médico-assistencial, e política, para legitimar o projeto da saúde junto à administração municipal e aos demais atores sociais vinculados ao setor, acumulando poder para a equipe dirigente da SMS. Vale ressaltar que a racionalidade hegemônica dessa prática era de natureza política, o que não a confunde, entretanto, com improvisação.

Verificou-se, no caso sob estudo, a existência do planejamento sob a forma de deter- 
minadas práticas estruturadas, realizadas por força das exigências legais da administração pública brasileira. A ritualização das práticas estruturadas de planejamento encontrada nesta secretaria reforça as conclusões dos estudos sobre descentralização da saúde no país 10,11 quanto à "burocratização" do planejamento em municípios que assumiram a responsabilidade pela gestão dos sistemas de saúde. Situação que encontra eco em governos da América Latina, refletindo a imaturidade institucional dos países desse continente, o que torna o planejamento um mero exercício de retórica, um "espetáculo" para o público externo, com pouca repercussão sobre as práticas de gestão das organizações 22 .

Resultados semelhantes quanto à incipiência da incorporação de práticas estruturadas de planejamento em organizações públicas de saúde foram encontrados em dois estudos que se debruçaram sobre o modus operandi de secretarias estaduais de saúde 23,24. Mantinham-se, nas duas instituições, os mesmos procedimentos ritualísticos para a elaboração das propostas orçamentárias.

A SMS tinha um projeto de governo coerente com o programa da administração municipal, expressão do compromisso político com a oferta universal de serviços sociais à população. Esse projeto tinha forte consenso interno, compartilhado entre equipe dirigente da SMS e técnicos responsáveis pela operação da atenção à saúde da população. As ações empreendidas pela SMS para a implementação das políticas de saúde pareciam estar muito mais baseadas nos valores compartilhados entre dirigentes e parte dos servidores quanto ao que consideravam justo em termos da oferta de serviços de saúde à população, do que numa racionalidade técnico-sanitária, em que critérios de priorização de danos e riscos à saúde orientassem a alocação de recursos financeiros.

Aderir aos programas e projetos aprovados na Comissão Intergestores Tripartite (CIT), com a forte influência do Ministério da Saúde, foi a forma encontrada pela SMS investigada para aumentar substancialmente o volume de recursos públicos destinados ao setor saúde, decisão que lhe proporcionou acúmulo de poder administrativo e político. Entretanto, essa decisão tornava-se, contraditoriamente, motivo para desgaste junto ao núcleo dirigente da administração municipal, por implicar em aumento dos gastos com recursos próprios, além de provocar um receio político de perda da governabilidade pela impossibilidade de atender à crescente demanda social por serviços de saúde, dada a insuficiência de recursos financeiros.
No Brasil, a formulação das políticas de saúde em um fórum nacional de negociação intergestores (CIT) pode ser um limite à incorporação de práticas de planejamento ao trabalho da gestão no âmbito municipal. Ao final, cabe aos municípios aceitar imposições travestidas de escolhas, num contexto de grande dependência financeira do Governo Federal. Contudo, a legislação brasileira assegura autonomia municipal. O planejamento, como prática de gestão, poderia contribuir para organizar intervenções de saúde mais próximas das necessidades locais.

Apesar do efetivo apoio político dos prefeitos à implantação do SUS em seu território, a governabilidade da equipe dirigente da SMS, para a implementação das políticas de saúde, também sofria restrições locais, visto que dispunha de uma autonomia administrativo-financeira "tutelada" pela administração municipal. Havia um alto grau de "fricção burocrática" 25, evidenciado pelo tempo despendido pela equipe com as negociações com as secretarias sistêmicas para a realização de procedimentos administrativos rotineiros e indispensáveis ao bom funcionamento das unidades de saúde.

A governabilidade da equipe dirigente da SMS pode ser caracterizada como limitada. Esse ator social encontrava-se submetido aos constrangimentos externos provocados pelo modelo de financiamento do SUS e à tutela da Prefeitura Municipal sobre os procedimentos administrativos necessários ao funcionamento da rede de serviços de saúde. Contudo, a perícia dos dirigentes em construir viabilidade política para a implantação do SUS municipal, especialmente junto ao Ministério da Saúde, principal fonte de apoio externo, permitiu-lhe o acúmulo de poder, fundamental para a condução de seu projeto de governo.

Os componentes da equipe dirigente eram sujeitos constituídos na ação, orientados por princípios políticos que os levava a uma atitude implicada em seu trabalho na construção do SUS municipal. Essa implicação permitiu a esses sujeitos a articulação entre as racionalidades técnica e política em sua prática de gestão 26 , um dos elementos responsáveis pelo avanço obtido na implantação do SUS municipal num contexto anterior marcado pela omissão do poder executivo na prestação de serviços de saúde à população.

Há que se destacar que a capacidade de governo não se restringe apenas à perícia da equipe dirigente, composta pela conjunção de conhecimentos, experiência e exercício da liderança. Inclui, também, os sistemas de trabalho, expressão concreta das práticas de gestão realizadas por uma dada organização, e o desenho organizativo da instituição. 
A ausência de institucionalização de práticas estruturadas de planejamento concorreu para fragilizar a capacidade de governo da equipe dirigente da SMS, na medida em que não sustentou ações sistemáticas de programação, monitoramento e avaliação das atividades realizadas pela organização. No caso estudado, a incipiência dos sistemas de trabalho da SMS e um desenho organizativo insuficiente para sustentar a consolidação do SUS no município indicam que a capacidade de governo da equipe dirigente restringia-se à sua perícia.

Pode-se afirmar que, no caso estudado, o projeto de governo foi o vértice mais robusto do triângulo matusiano ao requerer o desenvolvimento de certa perícia da equipe dirigente, embora limitada, que, por sua vez, contribuiu para ganhos de poder, assegurando-lhe relativa governabilidade sobre a condução do projeto da saúde.

Quanto ao uso do planejamento como ferramenta de gestão, considerado como a expressão de um método, pode-se inferir que a restrição do exercício de práticas de planejamento estruturadas e não estruturadas para parte da equipe dirigente da SMS e em situações operacionais muito específicas, a exemplo do trabalho de uma equipe de saúde da família, revelava, também, a incipiência do próprio método e sua pequena capacidade de contribuir com o fortalecimento da organização.

A precariedade do método e a debilidade da organização SMS restringiram as possibilidades de manutenção do propósito de crescimento da oferta de serviços de saúde, ameaçando, também, o propósito de legitimidade do grupo político que administrava o município estudado, numa situação em que o município não detinha a governabilidade sobre o financiamento da saúde e nem a equipe dirigente controlava de modo autônomo a gestão financeira dos procedimentos necessários ao funcionamento adequado da rede municipal de serviços de saúde.

O papel do Estado impôs limites aos propósitos de crescimento da oferta de serviços de saú- de no município estudado, em função do caráter contraditório da implementação do SUS diante da hegemonia neoliberal na condução de políticas econômicas de ajuste fiscal vigentes no Brasil desde a década de 90 27. Nesse contexto, há uma permanente tensão entre as restrições impostas pela política econômica e a implementação de políticas sociais compensatórias.

\section{Considerações finais}

No município estudado, os modos pelos quais ocorreram as conexões entre a formulação de diretrizes políticas e sua operacionalização nos serviços de saúde estiveram associados ao compartilhamento de valores entre equipe dirigente e profissionais da SMS. Nesse sentido, o planejamento, em seu formato não estruturado, ainda que como exercício limitado aos dirigentes, contribuiu para conduzir as ações de saúde no âmbito municipal, segundo os preceitos legais que regem o SUS, mediante a articulação entre as racionalidades técnica e política que lhe eram subjacentes, dado que esses sujeitos estavam implicados com o projeto do SUS democrático.

Pode-se concluir que houve uma modulação entre projeto de governo, capacidade de governo e governabilidade para implementar políticas de saúde na secretaria municipal. No caso investigado, o projeto de governo foi o componente mais forte do triângulo de governo. $\mathrm{O}$ papel do Estado determinou os propósitos de governo, considerando a existência de contradições internas no aparelho estatal, que, ao tempo em que possibilitaram a implantação do SUS municipal, ameaçavam sua sustentabilidade. Os propósitos de governo da SMS foram condicionados pela fragilidade do método e pela incipiência da organização, que se configuraram como limites locais à sustentação do SUS como política universal de atenção à saúde da população, comprometendo a governabilidade da equipe dirigente da SMS. 


\section{Resumo}

O exercício de práticas de planejamento para implementar políticas de saúde pode ocorrer em experiências municipais exemplares quanto à ampliação do acesso da população aos serviços de saúde. O estudo buscou analisar os limites e as possibilidades das práticas de planejamento na implementação de políticas em uma secretaria municipal de saúde. O estabelecimento de um conceito de práticas de planejamento e a articulação teórica entre o triângulo de governo e o postulado de coerência sustentaram a análise dos dados empíricos. A realização de práticas não estruturadas de planejamento, de natureza estratégica, pela equipe dirigente, permitiu a ampliação significativa da oferta de serviços à população, mas não teve amplitude para superar os limites que o modelo de financiamento das ações de saúde, sob forte indução federal, impunham à governabilidade dessa organização. O projeto foi o vértice mais robusto do triângulo de governo e levou ao desenvolvimento de certa perícia da equipe dirigente, assegurando-lhe relativa governabilidade sobre o projeto de saúde. Os propósitos de crescimento da oferta dos serviços de saúde foram condicionados pela fragilidade do método e pela incipiência institucional da organização.

Planejamento em Saúde; Gestão em Saúde; Política de Saúde; Sistemas Locais de Saúde

\section{Referências}

1. Viana AL. Abordagens metodológicas em políticas públicas. Rev Adm Pública 1996; 30:5-43.

2. Schraiber LB, Peduzzi M, Sala A, Nemes MIB, Castanhera E, Kon R. Planejamento, gestão e avaliação em saúde: identificando problemas. Ciênc Saúde Coletiva 1999; 4:221-61.

3. Rivera FJU, Artmann E. Planejamento e gestão em saúde: flexibilidade metodológica e agir comunicativo. In: Rivera FJU, organizador. Análise estratégica e gestão pela escuta. Rio de Janeiro: Editora Fiocruz; 2003. p. 17-35.

4. Fleury M-J, Denis J-L, Sicotte C. The role of regional planning and management strategies in the transformation of the healthcare system. Health Serv Manage Res 2003; 16:56-69.

5. Green A. The state of health planning in the ' 90 s. Health Policy Plan 1995; 10:22-8.

\section{Colaboradores}

A. L. Q. Vilasbôas redigiu o artigo. J. S. Paim revisou o artigo.
6. Arretche M. A política da política de saúde no Brasil. In: Lima NT, Gerschman S, Edler FC, Suárez JM, organizadores. Saúde e democracia: história e perspectivas do SUS. Rio de Janeiro: Editora Fiocruz; 2005. p. 285-306.

7. Marques RM, Mendes A. Atenção básica e Programa de Saúde da Família (PSF): novos rumos para a política de saúde e seu financiamento? Ciênc Saúde Coletiva 2001; 6:269-91.

8. Viana ALd'A, Heimann LS, Lima LD, Oliveira RG, Rodrigues SH. Mudanças significativas no processo de descentralização do sistema de saúde no Brasil. Cad Saúde Pública 2002; 18 Suppl:139-51.

9. Collins C, Araújo J, Barbosa J. Decentralising the health sector: issues in Brazil. Health Policy 2000; 52:113-27. 
10. Heimann LS, coordenadora. A descentralização do sistema de saúde no Brasil - uma proposta de investigação sobre o impacto das políticas. São Paulo: Instituto de Saúde; 1998.

11. Gerschman S. Municipalização e inovação gerencial. Um balanço da década de 90. Ciênc Saúde Coletiva 2001; 6:417-34.

12. Giordani JA. La planificación como proceso social: un esquema de análisis. Cuadernos Sociedad Venezolana de Planificación: Teoría y Método de la Planificación 1979; 3:147-77.

13. Matus C. Política, planejamento e governo. Brasília: Instituto de Pesquisa Econômica Aplicada; 1993. (Série IPEA, 143).

14. Paim JS. Aspectos críticos da institucionalização da planificação em organizações públicas de saúde. In: Paim JS, organizador. Saúde, política e reforma sanitária. Salvador: Centro de Estudos e Projetos em Saúde/Instituto de Saúde Coletiva, Universidade Federal da Bahia; 2002. p. 407-33.

15. Campos RO. O planejamento no labirinto: uma viagem hermenêutica. São Paulo: Editora Hucitec; 2003.

16. Weber M. Economia e sociedade. 3a Ed. Brasília: Editora UnB; 1994.

17. Habermas J. Teoría de la acción comunicativa. Madrid: Taurus; 2000

18. Mendes-Gonçalves RB. Tecnologia e organização social das práticas de saúde: características tecnológicas do processo de trabalho na rede estadual de centros de saúde de São Paulo. São Paulo: Editora Hucitec/Rio de Janeiro:ABRASCO; 1994.
19. Testa M. Pensar en salud. 3a Ed. Buenos Aires: Lugar Editorial; 2004.

20. Vieira-da-Silva LM, Hartz ZMA, Chaves SCL, Silva GAP, Paim JS. Análise da implantação da gestão descentralizada em saúde: estudo comparado de cinco casos na Bahia, Brasil. Cad Saúde Pública 2007; 23:355-70.

21. Denis J, Champagne F. Análise da implantação. In: Hartz ZMA, organizadora. Avaliação em saúde: dos modelos conceituais à prática na análise de implantação de programas. Rio de Janeiro: Editora Fiocruz; 1997. p. 49-88.

22. Matus C. O líder sem estado-maior. São Paulo: Fundação do Desenvolvimento Administrativo; 2000.

23. Coelho TCB, Paim JS. Processo decisório e práticas de gestão: dirigindo a Secretaria da Saúde do Estado da Bahia, Brasil. Cad Saúde Pública 2005 21:1373-82.

24. Lotufo M. Gestão pública em saúde: análise da capacidade de governo da alta direção da SES-MT em 2001 [Tese de Doutorado]. Salvador: Instituto de Saúde Coletiva, Universidade Federal da Bahia; 2003.

25. Matus C. Los 3 cinturones del gobierno. Caracas: Fondo Editorial Altadir; 1997.

26. Spinelli H, Testa M. Del diagrama de Venn al Nudo Borromeo: recorrido de la planificación en América Latina. Salud Colectiva 2005; 1:323-35.

27. Gerschman S, Viana ALd'A. Descentralização e desigualdades regionais em tempos de hegemonia liberal. In: Lima NT, Gerschman S, Edler FC, Suárez JM, organizadores. Saúde e democracia: história e perspectivas do SUS. Rio de Janeiro: Editora Fiocruz; 2005. p. 307-51.

Recebido em 02/Ago/2007

Versão final reapresentada em 24/Out/2007 Aprovado em 23/Nov/2007 